\title{
AS CONTRIBUIÇÕES DO SUBPROJETO PIBID/HISTÓRIA DA UNICENTRO PARA A PROFISSIONALIZAÇÃO DOCENTE, IRATI- PR (2012-2014)
}

\author{
CONTRIBUTIONS OF SUBPROJECT PIBID/UNICENTRO HISTORY FOR \\ PROFESSIONAL TEACHER, IRATI-PR (2012-2014)
}

\author{
Claércio Ivan Schneider ${ }^{1}$ \\ Silvéria Aparecida Ferreira ${ }^{2}$
}

\begin{abstract}
RESUMO: Com esta pesquisa buscamos compreender a importância, as contribuições e os significados do Programa Institucional de Bolsa de Iniciação à docência (PIBID) para 0 processo de profissionalização dos licenciandos participantes do Subprojeto PIBID História da UNICENTRO - Campus Irati-Pr., no período que compreende os anos de 2012 a 2014. A fim de analisar o perfil do profissional de História que está sendo construído, em especial pela experiência do PIBID, desenvolvemos discussões acerca de dois pilares que fundamentam o campo teórico prático do subprojeto: consciência histórica e formação de professores. A partir de entrevistas dirigidas aos pibidianos, buscamos entender como o programa e o subprojeto propiciam a articulação e a ressignificação da disciplina de História na escola, bem como, compreender o significado deste ambiente escolar enquanto laboratório para o pibidianos desenvolverem diferentes dimensões de sua profissionalização.
\end{abstract}

Palavras chaves: Pibid. Profissionalização docente. Consciência histórica.

\begin{abstract}
With this research we aimed to understand the importance, the contributions and the meaning of the Institutional Program of Grants for the Initiation of Teaching Practice (PIBID) for the process of professionalization of undergradute students that participate in the subproject PIBID History at UNICENTRO campus of Irati-PR, during the period of 2012 to 2014. In order to analyze the profile of the professional that is being built, particularly those undergoing the PIBID experience, we developed discussions about two pillars that fundament the theoric field of the subproject: historical conscience and the formation of teachers. Through interviews with the participants we tried to understand how the program and the project promote the articulation and the resignification of the subject of History at the school, as well as to understand the meaning of the school environment as a laboratory for the participants to develop different dimensions of their profissionalization.
\end{abstract}

Keywords: Pibid. Teaching professionalization. Historical conscience.

\footnotetext{
${ }^{1}$ Doutorado em História (UNESP - Assis). Professor do Programa de Pós-Graduação em História da Unicentro, Campus de Irati-Pr.

${ }^{2}$ Licenciada em História - Unicentro, Campus de Irati-Pr.
} 


\section{Introdução:}

O Programa Institucional de Bolsa de Iniciação à Docência (PIBID) constitui-se em uma iniciativa do governo federal de valorização e aperfeiçoamento na formação de professores para a educação básica. Decorre da lei 11.502 de 11 de julho de 2007, que incumbiu à Coordenação de Aperfeiçoamento de Pessoal de Nível Superior - Capes, a tarefa de induzir e fomentar a formação inicial e continuada de profissionais da Educação básica, bem como, a valorização do magistério em todas as modalidades de Ensino. A CAPES procurou trabalhar em projetos que articulassem três vertentes: formação de qualidade; integração entre pós-graduação, formação de professores e escola básica; e produção de conhecimento. O projeto PIBID $^{3}$ foi um dos que mais destacou-se pela originalidade e legitimação, considerando também seu crescimento acentuado de 2007 até agora.

Relevante para essa discussão os dados quantitativos do Programa, a exemplo na Universidade Estadual do Centro-Oeste o PIBID foi implementado em 2010 (Edital 002/2009-CAPES/DEB), contava com apenas seis subprojetos (Matemática, Pedagogia, Química, Física e Arte-Educação no campus de Guarapuava e Letras Português no campus de Irati), ao todo 89 bolsas contando com bolsistas de iniciação, supervisores e coordenadores de área. Em agosto de 2011, um novo projeto institucional (Edital 01/2011-CAPES/DEB), nesse foram contemplados oito subprojetos nessa instituição, esse novo grupo é constituído no total de 120 membros. Esse novo projeto foi ampliado em agosto de 2012 quando foram incluídos outros nove subprojetos, contando agora com 315 membros envolvidos com o Programa Institucional de Bolsa de Iniciação à Docência. Atualmente todos os cursos de licenciatura da Universidade Estadual do Centro-Oeste possuem subprojetos envolvidos no projeto institucional do PIBID.

De forma geral, o PIBID constitui-se em um programa que alia a tríade Ensino, Pesquisa e Extensão, proporcionando um contato de maior intensidade dos bolsistas, futuros professores, com seu campo de trabalho, uma vez que o

\footnotetext{
${ }^{3}$ Diretoria de Educação Básica Preferencial - DEB; PIBID/CAPES. Relatório de Gestão 2009-2012. Disponível em: http://www.capes.gov.br/images/stories/download/bolsas/DEB Pibid Relatorio2009 2011.pdf Acesso em: 26/05/2014. Ver também: http://www.capes.gov.br/educacaobasica/capespibid.
} 
projeto envolve o planejamento da ação didática, centrado na observação, na pesquisa, na experimentação e na intervenção. Os participantes desse programa conseguem diferenciarem-se dos demais licenciandos na medida em que desenvolvem habilidades e competências no campo de trabalho, obtendo experiências ímpares da prática, muito antes de entrarem nesse mercado.

O Programa Institucional de Bolsa de Iniciação à docência vem mostrando-se como um dos grandes fomentadores da profissionalização docente, visto que se alia ao Estágio Obrigatório da Universidade. Mais do que isso, ao envolver o licenciando na escola por um tempo muito superior a carga do Estágio Supervisionado ${ }^{4}$, este programa fomenta uma formação plural, pautada tanto nas metodologias de ensino aprendizagem quanto no reconhecimento do campo profissional e de gestão escolar. Nesse sentido, o PIBID também proporciona a possibilidade de um contato mais intenso com os problemas da escola, as falhas do sistema educacional, os pontos positivos da profissão, os planos de carreira. E tudo isso agrega conhecimento, experiência e autonomia aos futuros profissionais do ensino.

Desenvolvido no espaço da escola o programa propícia uma aproximação particular do futuro profissional do ensino com o cotidiano e a dinâmica escolar. Os bolsistas devem dedicar no mínimo oito horas semanais ao projeto, cumprindo essas horas na escola, supervisionados por um professor titular e orientados pelo coordenador do subprojeto. Importante destacar que a realidade do PIBID é resultado da confecção, por parte das instituições de ensino superior, de um projeto institucional que engloba os cursos de licenciatura. $O$ projeto institucional - sob responsabilidade de uma coordenadora institucional - é composto por diferentes subprojetos, respeitando as especificidades de cada curso de licenciatura ofertado na universidade. O subprojeto deve ser de autoria de um coordenador com currículo e atuação direta no campo do ensino de sua área. No caso específico da UNICENTRO, entre os anos de 2012 a 2014,

\footnotetext{
${ }^{4}$ O Estágio Supervisionado em História na Unicentro é dividido em dois anos, com carga horária total de 400 horas. A primeira etapa é no terceiro ano da graduação, os discentes cursam a disciplina de Estágio Supervisionado I, que possui carga horária de 200 horas, sendo essas: 136 (cento e trinta e seis) horas de aulas teóricas e práticas; 10 (dez) horas de atuação; 12 (doze) horas de regência no ensino fundamental e 42 (quarenta e duas) horas de reuniões do discente em estágio com o docente supervisor, para discussão e elaboração dos planos de aula e das atividades de regência e na preparação e finalização do relatório de estágio. Assim como o Estágio Supervisionado II que é cursado no quarto ano do curso, e realiza-se as observações e a prática no Ensino Médio (Regulamento de Estágio. CONDEP, 2009, p.04).
} 
praticamente todos os cursos de licenciatura foram contemplados pelo programa, repercutindo num número significativo de pibidianos privilegiados com 0 recebimento de bolsas da Capes.

Este artigo tem como objetivo problematizar as contribuições do Pibid, em especial as contribuições do subprojeto PIBID-História desenvolvido na Unicentro, Campus de Irati, para com a formação docente dos professores iniciantes. Ou seja, busca-se, de um lado, analisar o perfil do profissional do ensino gestado a partir da "grade" curricular do Projeto Político do Curso de História de Irati (PPCH-I) e, de outro lado, analisar a relevância do subprojeto Pibid para a ressignificação da profissionalização do docente em História. Para tanto, objetiva-se compreender os significados e a importância que os próprios pibidianos atribuem ao programa e em especial ao subprojeto Pibid-História. Nesse sentido, realizamos uma pesquisa através da aplicação de questionário aos pibidianos que fizeram parte do subprojeto de Agosto de 2012 a Março de 2014. A partir das falas dos pibidianos podemos compreender a singularidade do programa e do subprojeto na formação profissional dos licenciandos e, além disso, ponderar sobre como a experiência do PIBID vem a superar as lacunas formativas que a limitada prática dos Estágios Supervisionados proporciona.

Com este itinerário, buscamos problematizar os dados obtidos e identificar os acertos, os problemas, as indagações, as frustrações e as aspirações dos pibidianos quanto a sua profissionalização. Além disso, identificar as contribuições do subprojeto e a originalidade do programa a partir da fala dos bolsistas implica problematizar o papel social da Universidade e, em especial, do curso de História na formação do profissional de ensino. Buscamos entender como o programa e o subprojeto propiciam a articulação e a ressignificação da disciplina de História na escola, bem como, compreender o significado deste ambiente escolar enquanto laboratório para o pibidianos desenvolverem diferentes dimensões de sua profissionalização para a docência. 


\section{O PIBID no campo formativo das licenciaturas: histórias e historiografias}

A preocupação para com o campo de pesquisa em torno da profissionalização de professores mobiliza inúmeros autores em diferentes áreas do conhecimento. Formação docente, gestão escolar, práticas de ensino, novas tecnologias, novas linguagens, etc., constituem-se em alguns temas chaves deste campo, em especial no campo da História. Em torno do PIBID, no entanto, ainda pouco se produziu em termos de historiografia. $O$ fato de ser um programa recente e de estar focado essencialmente no ensino talvez ajude a explicar esta inibição aparente. Aparente porque gradativamente surgem pesquisas originadas das experiências do PIBID em diferentes contextos sociais e em diferentes cursos de licenciaturas. Nesse sentido, algumas discussões sobre o PIBID estão sendo gestadas no campo científico das universidades. Como este programa está disseminado em muitas instituições do Brasil, atendendo uma forte demanda de uma grande área, alguns resultados já podem ser vistos a partir da produção de inúmeros artigos, a maioria de autoria discente, que apresentam as diferentes e originais propostas de ensino e de formação docente arregimentadas a partir do PIBID. Artigos resultantes, muitas vezes, da participação e da apresentação de trabalhos dos pibidianos em eventos, bem como trabalhos de conclusão de curso de graduação, que é a característica deste texto.

De início, o que observamos como ênfase discursiva em torno desta ainda incipiente historiografia em torno do PIBID é a impressão elogiosa do programa. Inúmeros acadêmicos, gestores, professores e pesquisadores relatam os benefícios que tal iniciativa governamental trouxe ao campo formativo das licenciaturas. Na Universidade Federal do Rio Grande do Sul, por exemplo, no que compreende o subprojeto PIBID de História, Carla B. Meinerz (2013, p. 224) afirma:

Considero a inserção na docência em História, através dos estágios curriculares obrigatórios e do Programa Institucional de Bolsas de Iniciação à Docência (PIBID), como um processo de impactos, por vezes inimagináveis, na trajetória dos licenciandos, aqui compreendidos como professores em formação inicial. 
Quando Meinerz (2013) faz menção ao "inimaginável", refere-se ao inesperado, ao encontro com o oculto, tanto para os professores da Universidade, no papel de formadores de profissionais críticos, quanto aos discentes, alunos em processo de formação. Esse encontro dos discentes com a realidade escolar, simbolicamente representada pelo inimaginável, também constitui-se em uma forma de deparar-se com a beleza do inesperado, do desconhecido. O Estágio curricular e o PIBID proporcionam aos licenciandos o contato com o imprevisto, descoberto aos poucos pela convivência através da inserção no cotidiano escolar. Ainda com Meinerz (2013, p.224):

\footnotetext{
Experimentar pela primeira vez as complexidades da sala de aula e dos tempos/espaços escolares é, por si só, enfrentar situações inesperadas. A inserção inicial na docência é composta por imaginários que o estudante possui em relação ao que seja a escola, a universidade, o curso de História, as disciplinas do campo da educação, o ensino, a pesquisa, as relações sociais, entre outros.
}

Os imaginários construídos em torno da inserção na docência evidenciam um campo complexo de atuação sempre que os acadêmicos deparam-se com o cotidiano escolar. Suas visões muitas vezes são "embaçadas" pelas teorias e pouco fundamentadas na realidade do futuro campo de trabalho. Acreditamos que o contato direto com o dia a dia da escola é fundamental para o professor em formação compreender as diferentes dimensões da educação básica brasileira, formando competências e habilidades segundo a realidade imediata na qual estão inseridos. Nesse sentido, o estágio supervisionado e o Pibid agregam dimensões formativas imprescindíveis à formação do futuro profissional do ensino.

Quanto ao PIBID, Meinerz (2013, p. 232) atribui relevância significativa ao seu papel formador, ou seja, enquanto programa de importância singular para a trajetória da profissionalização dos licenciandos na medida em que se constitui de possibilidades de experimentação. Segundo esta autora, os pibidianos "entendem igualmente que o labor diário do professor de História é diferenciado em relação ao experimentado como pibidiano e docente em formação, construindo processos de respeito, crítica e aprendizagem". 
Em outro artigo que resulta das experiências do PIBID de História da Universidade Federal de Santa Maria, em 2009, Linhares e Pereira (2013, p.1104) relatam as especificidades formativas arregimentadas. As autoras focam as ações desenvolvidas no projeto e a relação diferenciada com o Ensino de História. Através de oficinas dinâmicas, em especial em torno do cinema, realizaram atividades dando ênfase para processos históricos complexos: "As oficinas buscaram suscitar uma reflexão teórica e prática acerca da realidade dos estudantes levando em consideração os conhecimentos empíricos dos mesmos e problematizando outras reflexões sobre seu cotidiano".

Linhares e Pereira destacam a oportunidade de se trabalhar na escola na forma de oficinas ${ }^{5}$. Metodologia que, segundo elas, oportunizou reflexões teóricas e práticas que levaram em consideração os conhecimentos dos alunos. Para os integrantes desse subprojeto, partir de oficinas para dinamizar as aulas tornouse um aparato importantíssimo para o Ensino de História, na medida que conseguiram superar a tradicional instância formativa pautada quase que exclusivamente no ensino por meio do livro didático.

Mas as experiências formativas arregimentadas a partir do PIBID não serão transformadoras se o corpo docente das universidades não buscar também sua transformação. Segundo Vera Lúcia M. Barroso (2013, p.10), o corpo docente deve assumir o compromisso de "entrosar-se" para acrescentar na formação profissional do acadêmico primando pela apropriação do significado social da ciência histórica. A autora defende a necessidade de incorporar aos objetos de estudo contemporâneos a discussão da formação de professores, tornando-se tarefa urgente dos cursos de licenciatura na área. Segundo a autora:

O propósito esperado é formar profissionais em História com conteúdos, competências e habilidades focados na área de conhecimento, no sentido de poder atuar com autonomia intelectual e responsabilidade social, face ao seu papel sóciohistórico nos espaços de trabalho em sua área de conhecimento e na sociedade em que vive (BARROSO, 2013, p. 12).

A autora deixa claro que para potencializar uma formação acadêmica qualificada para o desempenho da docência e para a produção de conhecimento

\footnotetext{
${ }^{5}$ Para uma discussão em torno da importância do ensino por meio de oficinas, consultar o artigo da professora portuguesa Isabel Barca, Intitulado: "Aula oficina: do projecto à avaliação", publicado na obra Para uma Educação Histórica de Qualidade, em 2004.
} 
histórico são necessários estabelecer vínculos que devem estar articulados às Diretrizes Curriculares da Educação Básica e aos Projetos Políticos Pedagógicos dos cursos de licenciatura das Universidades. Vínculos que coloquem em cheque uma formação tecnicista, apontando para novas habilidades e competências no sentido de uma construção contracultural, ou seja, que questione a perspectiva oficial e midiática que padroniza o ensino e os conteúdos. Sobre os Estágios obrigatórios e o PIBID a autora afirma:

[...] constituem-se em laboratórios para o exercício prático de conexões, apontadas como anunciadoras da construção de uma contracultura, que se anteponha a uma visão tecnicista de formação, animada pela força e imposição que o poder das mídias vem firmando em diferentes cenários das relações humanas e nos diversos espaços sociais (BARROSO, 2013, p. 12).

Barroso assegura que os cursos de licenciatura vêm perdendo candidatos devido a tantas desvalorizações que a profissão agrega, tais como salários baixos e a falta de reconhecimento por parte dos alunos que estão "ligados" em tudo que a mídia passa e desconsideram o professor em sala com o quadro e giz. Não se trata de uma visão pessimista, segundo a autora, mas sim de uma análise de conjuntura. Para melhorar a situação o Estado vem apresentando algumas políticas, como o PIBID, que segundo Barroso (2013, p.13), "trata-se de interessante oportunidade de estreitar laços entre a universidade e a escola básica, como também de motivar os graduandos a seguirem como professores, decididos a intervirem nos espaços escolares em defesa de sua melhoria e qualidade". O PIBID é entendido como um programa que pode agregar novos significados ao Ensino, dando espaço para diferentes intervenções neste campo, auxiliando na necessária e urgente ressignificação da formação do profissional de História.

Como estamos vendo, a original dimensão formativa que o PIBID gradativamente está assumindo no contexto escolar torna as opiniões e as narrativas de diversos professores e alunos, de diferentes instituições e contextos sociais, homogêneas, principalmente no que diz respeito ao reconhecimento da importância e da eficácia do programa no campo formativo, em especial da História. As contribuições do PIBID parecem incontestáveis e alguns resultados mostram que sua eficácia tem valor único no campo das 
licenciaturas. Várias falas são significativas para mostrar esta eficácia. Falas como a do professor Jerônimo Sartori, coordenador de um subprojeto PIBID na área de Ciências Biológicas, quando afirma:

O Programa Institucional de Bolsa de Iniciação à Docência - PIBID, sem dúvida, constitui-se numa das alternativas potenciais para fortalecer a formação inicial, considerando as conexões entre os saberes que se constroem na universidade e os saberes que cotidianamente são produzidos e se entrecruzam nas unidades escolares. A experiência real do professor em exercício na educação básica é relevante por enriquecer a formação inicial e profissional dos licenciandos, bolsistas do programa, uma vez que estes entram em contato direto com a realidade vivenciada diariamente pelos professores de ensino fundamental e de ensino médio (SARTORI, 2011, p.02).

O PIBID é entendido como alternativa potencial para o fortalecimento da formação inicial. Possibilita a conexão entre os saberes, a observância da experiência real do professor em exercício bem como a compreensão da realidade escolar.

Estas discussões em torno das potencialidades do programa PIBID ilustram o que estamos vivenciando a partir do trabalho desenvolvido no Subprojeto de História da Unicentro, campus de Irati-Pr. O coordenador Claércio Ivan Schneider evidencia que o compromisso para com a formação docente deve nortear as atividades de ensino aprendizagem planejadas e desenvolvidas na escola, segundo suas especificidades. Para isso foi fundamental a estipulação de metas, de objetivos e de ações para uma intervenção consciente e segura dos pibidianos no campo de atuação. Segundo o autor, o subprojeto:

[...] tem o compromisso de buscar ressignificar o campo formativo do profissional do ensino de História. Compromisso que implica fazer com que o futuro profissional crie consciência histórica de seu campo formativo e que se fortaleça a partir de uma identidade profissional construída no campo de atuação, o espaço escolar, entendido como um laboratório para se gestar e se executar diferentes experiências de ensino e de aprendizagem (SCHNEIDER, 2013, p.05).

Ressignificar o campo formativo a partir do estímulo à formação da consciência histórica dos futuros professores de História para com o seu campo de atuação é meta central do subprojeto. O investimento está no fortalecimento 
de uma identidade profissional. A escola entendida como laboratório e o professor supervisor como referência profissional favorecem o planejamento e a execução de atividades que na universidade seriam impossíveis de se arregimentar. O processo de construção e desenvolvimento da consciência histórica torna-se essencial para a formação profissional dos licenciandos. Eles conseguem aliar às experiências práticas na escola as teorias debatidas na universidade a fim de orientar suas concepções de ensino, de história e de sociedade. Nessa perspectiva, o PIBID assume importante função, no que diz respeito à formação da identidade profissional e da consciência histórica do acadêmico, futuro professor. Este necessita ter autonomia, iniciativa, personalidade, entre outras características, que podem ser gestadas através da prática e do reconhecimento do campo de trabalho.

\section{Projeto Pedagógico do Curso de História/I: Perfil do profissional desejado, Competências e Habilidades}

Os projetos pedagógicos dos cursos de licenciatura são fontes importantes para percebermos os caminhos formativos voltados à profissionalização docente. São documentos que evidenciam as competências e as habilidades que os licenciandos devem adquirir para o exercício de sua profissão. Importante destacar que mais do que profissionais da História, os cursos superiores de licenciatura formam profissionais para a vida, com o objetivo de atentarem para a realidade interpretando-a criticamente. Dessa forma, entender-se enquanto sujeito da própria história e interpretar criticamente as transformações dos sujeitos ao longo do tempo torna-se tarefa essencial para o acadêmico em formação. Os professores dos cursos de licenciatura deveriam ter como compromisso instigar nos discentes a consciência crítica para que, além de interpretarem o processo histórico, consigam problematizar, analisar e investigar o tempo presente. Ou seja, buscar formar profissionais pesquisadores e professores críticos, autônomos e hábeis a exercer sua função social e cultural. Função essa destacada no Projeto Pedagógico do Curso de História da Unicentro: 
[...] Trata-se de formar um profissional responsável e comprometido com a sociedade no que diz respeito à ampliação da cidadania e que atue com ética e espírito crítico, articulando o ensino de história com práticas de pesquisa e recursos diversificados e interdisciplinares ( $P P C H, 2010$, p.16).

Dentre os objetivos formativos impressos no $\mathrm{PPCH}$ um dos mais significativos é esse: tornar os acadêmicos preparados para olhar criticamente a sociedade. Objetivo pautado no compromisso ético e profissional do professor formador para com o exercício da cidadania, aguçando em seus pares e a quem mais puderem o anseio por seus direitos, principalmente à cidadania, a liberdade e a igualdade, ou seja, à consciência dos direitos e deveres políticos, sociais e civis. Para isso, além de estar apto a atuar nos diversos campos profissionais, o professor iniciante de História deve adquirir perfil social diferenciado, autônomo, respeitando sempre sua função frente a sociedade.

A Universidade emerge como um campo privilegiado de conhecimentos científicos cuja função é o desenvolvimento da consciência crítica dos acadêmicos e sua formação profissional. Nesse sentido, os acadêmicos devem ser munidos de habilidades, de conhecimentos, de argumentos e de aspirações, além de conseguirem formar uma visão de mundo acentuada, crítica e clara.

Trata-se de formar um profissional que possa atuar em todas as áreas nas quais o conhecimento histórico possa ser aplicável e necessário. Como historiador e profissional de ensino, o aluno deverá estar apto a aliar pesquisa e docência o que supõe pleno domínio da natureza do conhecimento histórico, das práticas essenciais de sua produção além de desenvoltura e domínio do saber relativo à docência $[\ldots](\mathrm{PPCH}, 2010$, p.16).

O PPCH defende o compromisso ambicioso para com a formação de historiadores e de profissionais do ensino com possibilidades de atuação em todas as áreas. Mesmo sendo um curso de licenciatura em História, o perfil pesquisador é também considerado central para que o futuro professor possa produzir saberes na área. A questão a ser pensada aqui é: será que o acadêmico, visto como professor que tem a responsabilidade de pensar historicamente, de produzir conhecimento e de promover a formação da consciência histórica dos próprios alunos, apresenta estas habilidades ou "desenvoltura e domínio" com tão poucas atuações obrigatórias durante o curso? De outro modo, o professor 
em formação consegue ter discernimento e autonomia para cumprir sua função social enquanto professor de História? Estas questões geram polêmicas na medida em que muitos acadêmicos parecem "perdidos" entre uma formação à pesquisa e outra à docência. A última frase da citação "desenvoltura e domínio do saber relativo à docência" reflete este problema. Como já destacado, a grade curricular do curso traz o Estágio Supervisionado com 400 horas totais, entretanto, desse montante apenas 44 horas são destinadas a pratica da docência.

Ser professor de História não constitui-se apenas em saber o conteúdo e ter domínio do mesmo, mas em ter a habilidade de interpretar o passado, observar e problematizar o mundo atual, além de fazer certas projeções para o futuro. Tal responsabilidade fica ainda maior quando em apenas 24 horas $^{6}$ os acadêmicos devem demostrar essa habilidade frente aos alunos, mesmo os estagiários terem a orientação do professor de Estágio Supervisionado. Ou seja, os acadêmicos se queixam que devido a esta carga diminuta de horas de estágio pouco podem desenvolver em habilidades, em desenvoltura e em saber relativo à docência. O Estágio Supervisionado, para muitos acadêmicos, torna-se um quesito burocrático de pouca eficiência, revelando as contradições do discurso do próprio PPCH.

Seguindo o projeto pedagógico do curso, destacamos as capacidades que os futuros profissionais da história devem agregar à sua formação, a partir de determinadas habilidades e competências, são elas:

Capacidade de questionar os fatos históricos, possuir métodos e
teoria que o possibilitem ir além da pura observação, construindo
um conhecimento crítico sobre os fatos históricos; Capacidade de
entender as fontes históricas em suas várias formas de se
apresentar; Capacidade de entender e produzir o discurso
historiográfico; Capacidade de construir o conhecimento histórico,
bem como transmitir esse conhecimento; Ser capaz de entender a
construção e o desenvolvimento da História enquanto ciência,
compreendendo a construção do conhecimento histórico; Respeito
às diversas formas das sociedades humanas se constituírem
historicamente; Capacidade de entender que a história, enquanto
ciência, se relaciona com outras ciências, mas possuí sua
especificidade; Capacidade de investigar um problema com

624 horas de regência na disciplina de Estágio Supervisionado (I e II), presentes na grade curricular do curso, sendo essas divididas em dois anos; no terceiro e no quarto ano do curso, no ensino fundamental e médio, respectivamente. 
justificativa, sabendo construir a pesquisa com delimitações, buscando as melhores fontes, os referências teóricos e metodológicos para o desenvolvimento da pesquisa; Capacidade de encontrar os melhores meios de transmissão do conhecimento histórico. (PPCH, 2010, p.15).

São muitas as competências e as habilidades necessárias à função da docência em História. Acima se destacam as características essenciais para os profissionais da área, sejam eles professores ou pesquisadores. No entanto, se pensarmos que o curso é de licenciatura percebemos que o Projeto Pedagógico do curso revela preocupações nitidamente voltadas ao pesquisador, ao Historiador, e não necessariamente ao professor. Ou seja, o currículo não se pauta no ideal da exclusividade na formação de professores, lembrando que a maioria destes professores recém-formados atuará na educação básica e poucos seguirão com a formação continuada, entendida aqui como o mestrado.

No currículo e a partir da teoria tudo parece adaptar-se, mas na prática nem tudo configura-se com êxito. Segundo Schneider há um certo desvio, uma deformação dessas competências ainda no espaço formativo dos estágios

Deformação atribuída aos currículos desatualizados, a dicotomia teoria-prática, a professores descomprometidos com sua função formativa, ou mesmo ao desinteresse generalizado dos próprios acadêmicos para com o campo da educação. Neste universo povoado por antagonismos e heterogeneidades de perspectivas as fórmulas prontas pouco auxiliam no processo formativo, aliás, este campo complexo deve ser entendido como fator constituinte da própria profissionalização. (SCHNEIDER, 2013, p. 06)

As universidades e os cursos de licenciatura não conseguem formar um profissional com habilidades e competências necessárias a intervenção na sociedade. Como visto, as contradições entre o formar-se professor e/ou historiador aliam-se a outras questões apontadas por Schneider. Neste sentido, o "ambiente escolar como espaço de profissionalização dos discentes" se torna alternativa imperativa para sanar deficiências que a universidade não consegue superar. Através do PIBID é possível ressignificar as habilidades e as competências no campo de atuação, buscando contemplar o perfil desejado do profissional de História segundo o PPCH. Profissional que, a partir da pesquisa, do planejamento e da ação constrói e reconstrói histórias, em suas diferentes 
dimensões, superando a carga limitada de estágio bem como as falhas que a grade curricular não consegue superar.

Os pibidianos estendem na escola relações com os debates feitos na Universidade favorecendo, dessa forma, cotidianamente, o desenvolvimento de novas habilidades e de novas competências. Buscam tornarem-se bons profissionais do ensino de História e para isso concedem aos seus alunos o aparato necessário para leva-los a aprimorar a própria consciência intelectual, de modo que a conscientização e a cidadania sejam as palavras chaves, visto que se pretende, na escola, formar cidadãos e não historiadores.

Por estas considerações em torno do currículo "real", ou seja, aquele que é executado na universidade, buscou-se fundamentar a contribuição formativa do PIBID, para isso entrevistamos pibidianos com o objetivo de perceber a importância que atribuem ao projeto em seu currículo formativo, principalmente voltado a construção de sua consciência histórica e do perfil profissional.

\section{Consciência histórica e formação docente: o papel do PIBID no currículo formativo do docente em História}

O conceito de Consciência Histórica torna-se passível de debate nessa pesquisa para que possamos compreender quão relevante tornou-se a combinação entre as teorias assimiladas na academia/Universidade e as práticas desenvolvidas na escola a partir do PIBID. Neste complexo campo formativo para a docência articularam-se saberes, competências e habilidades a fim de se contribuir para a formação de profissionais capacitados e críticos no campo educacional contemporâneo.

Para o professor Luis Fernando Cerri (2001, p.11), a consciência histórica pode ser entendida como característica constante dos grupos humanos. Todos são providos de consciência o que diferencia-nos é essencialmente como a utilizamos e de que forma a interpretamos, se é que interpretamos. Não é algo a ser alcançado, faz parte do pensamento humano, o que a desenvolve é o processo histórico, as experiências e práticas pelo qual ela passa, ou seja, pelo qual passamos. Cerri bebe das teorias do filósofo da História e alemão Jörn 
Rüsen, esse define o conceito de Consciência Histórica como: "(...) a suma das operações mentais com as quais os homens interpretam sua experiência da evolução temporal de seu mundo e de si mesmos, de forma tal que possam orientar, intencionalmente, sua vida prática no tempo" (RÜSEN, 2001. p. 58-59).

Segundo Rüsen (2001) para agir e orientar-se no mundo o homem, no seu sentido universal, precisa interpretá-lo, agir conforme sua intenção e seus desejos. Sendo assim, a consciência histórica é o que atribui sentido ao passado vivido, que tornou-se experiência no presente e orientação para o futuro. É necessário interpretar a sua volta, a si mesmo e ao tempo. Sendo assim, a vida é movida primeiramente pelas interpretações, a partir delas é que as ações são conscientes. Formar e atribuir sentido a própria consciência histórica é imprescindível para qualquer pessoa, mas é na figura do professor que torna-se essencial.

$\mathrm{Na}$ Universidade os docentes precisam instigar o grupo dos acadêmicos de forma coletiva, mas ao mesmo tempo individual, na tentativa de construir a consciência histórica do profissional iniciante, afim de que possa ressignificar o passado descobrindo novos sentidos e perspectivas para o presente e o futuro, mas para isso o docente precisa ter sua consciência histórica fundamentada e articulada com a realidade. Ressignificar, como afirma o professor Claércio, na tentativa de responder aos desafios que se apresentam à docência em história na atualidade em especial a atenção à formação docente e a constituição de uma identidade do professor de história (SCHNEIDER, 2013, p.1). É neste movimento que buscamos entender a constituição da consciência histórica arregimentada pelo grupo de acadêmicos participantes do PIBID. Consciência construída a partir da vinculação da teoria assimilada na Universidade com a prática vivenciada no cotidiano escolar.

No caso específico deste artigo, a consciência histórica dos pibidianos é construída a partir de um duplo movimento: de um lado, a partir das atividades desenvolvidas no subprojeto Pibid-História e, de outro lado, a partir da prática desenvolvida nos Estágios Supervisionados I e II. De início, a prática dos Estágios Supervisionados revela aos discentes uma realidade complexa no ambiente escolar: professores desmotivados, desinteressados e deprimidos com seu campo de trabalho. Realidade que faz entender que ser professor atualmente 
consiste em um desafio diário de ressignificação e de valorização permanente, principalmente devido ao desprestígio atual desta profissão. O que evidencia esta afirmação na atualidade é o baixo interesse dos jovens pelos cursos de licenciatura.

Desinteresse que acompanha o desprestígio da profissão de professor e também da própria disciplina de História: aulas desmotivadoras e distantes da realidade do aluno, preocupação com o ensino tecnicista e não humanista, falta de preparo e de interesse dos professores, formação continuada inexistente ou falha, desinteresse dos alunos, entre tantos outros motivos que poderiam ser citados e que já foram diagnosticados por inúmeros pesquisadores da área. 0 incentivo por parte das instituições preocupadas com a formação docente vem em forma de programas que tem a finalidade de diversificar, diferenciar, sensibilizar e ressignificar esse campo. No caso específico das licenciaturas, o programa PIBID reflete a tentativa governamental em atender a estas reivindicações.

As contribuições do Projeto Institucional de Bolsa de Iniciação à Docência tornaram-se evidentes, principalmente após tantos questionamentos e reflexões já apontadas. Para isso, produziu-se um roteiro de questões que foram respondidas por dez membros do subprojeto História/I desenvolvido entre agosto de 2012 a março de 2014 em duas escolas na cidade de Irati: Colégio João XXIII e Colégio São Vicente de Paulo.

A opinião dos pibidianos foi unanime quando perguntados sobre a importância e as contribuições do PIBID para o currículo formativo. Evidenciaram as singularidades do projeto e as melhorias específicas que cada sujeito adquiriu no decorrer do projeto. Essas por sua vez, continuarão existindo, pois os pibidianos dizem ter criado uma identidade profissional, que possivelmente não adquiriam sem esse contato mais intenso com o ambiente escolar e as experiências vivenciadas, que serviram para fomentar a própria consciência histórica. A construção da identidade do "ser professor" foi demostrada pelos pibidianos. Segundo Adriane Kaminski:

As intervenções em sala de aula, buscando inovar e dinamizar o ensino de História, foram essenciais na formação de uma identidade enquanto Professora, ajudou também a desenvolver de forma saudável autonomia para posicionar-se diante das turmas, 
além de proporcionar o domínio de alguns conteúdos e aprender a planejar uma aula mais elaborada (KAMINSKI, 2014).

As intervenções oportunizadas a partir do subprojeto, segundo Adriane, foram essenciais para a formação de sua identidade profissional. Essenciais na medida em que pode experimentar novas estratégias e metodologias de ensino que, com a prática, reforçaram a sua autonomia bem como proporcionaram certo domínio de conteúdos que na universidade não chegou a debater. Outro ponto importante destacado pela pibidiana refere-se ao planejamento "mais elaborado" das aulas. Isso se deve em especial pela consciência da realidade da turma em que atuou, respeitando as diversidades e buscando a partir do diálogo um ensino mais humanizado, mais vivo, desprendido do livro didático, uma vez que o compromisso dos pibidianos era o de buscarem materiais e fontes alternativas para as aulas que as supervisoras ministravam.

O PIBID também apresentou reflexos na vida pessoal dos bolsistas. A aquisição de autonomia, de segurança, de confiança e sobretudo a independência intelectual ultrapassam os muros da escola. Constituem-se em características que são levadas para todos os âmbitos da vida. O pibidiano Willian Franco Gonçalves ressalta seu desenvolvimento:

O PIBID ajudou muito na minha formação, antes do PIBID eu era uma pessoa mais tímida e sofria para apresentar trabalhos na faculdade e possivelmente sofreria ainda mais quando entrasse no mercado de trabalho. Mas com a ajuda do PIBID hoje já não tenho tanta vergonha de falar em público, ainda possuo minha timidez, mas agora posso controlá-la. Acredito que posso separar minha vida com o antes e o depois do PIBID (GONÇALVES, 2014).

Willian revela facetas muito comuns aos estudantes iniciantes: a insegurança, a timidez e o medo. Como vimos no PPCH, a formação para a docência implica a incorporação de diferentes competências e habilidades mas pouco se fala a respeito da condição social deste sujeito no campo universitário. A complexidade não se refere unicamente à perspectiva formativa mas ao próprio fazer-se enquanto sujeito. Na medida em que o pibidiano interage, vivencia e executa atividades de ensino aprendizagem, gradativamente vai construindo uma personalidade docente que lhe dá segurança e autonomia, conseguindo superar deficiências de personalidade, como destaca Willian. A superação dos medos e da timidez é possível em virtude do intenso contato com 
os alunos, com o colégio e com as supervisoras. Aliás, o diálogo, o planejamento e a intervenção nas aulas segundo as orientações das supervisoras também é determinante na formação da identidade profissional do pibidianos. Passar as experiências, apontar caminhos, perceber os problemas e as eventuais soluções e motivações são procedimentos fundamentais às supervisoras no acompanhamento dos alunos. Quanto ao papel das supervisoras, a pibidiana Márcia Scavinski afirma:

\begin{abstract}
Para realizar um bom trabalho é preciso, sem dúvida, de uma boa orientação e supervisão, contar com a ajuda de pessoas com mais experiência profissional é imprescindível. A professora supervisora observa, auxilia, aconselha sobre determinadas atitudes e procedimentos em sala de aula, enfatizando aqueles que precisam ser melhorados. Também é muito importante quando ela compartilha experiências da sua vida profissional, facilitando o processo de ensino/aprendizagem (SKAVINSKI, 2014).
\end{abstract}

Muitos professores moldaram seu jeito de ser a partir da identificação com um ou outro professor que teve ao longo da vida e, em especial, na universidade. Assim também é com o PIBID. Os bolsistas formam sua personalidade profissional a partir do que observam, do que discutem e do que planejam com as supervisoras. Elas, pela experiência, decodificam o campo de trabalho influenciando diretamente as concepções dos pibidianos acerca da escola, do ensino e da profissão. Nesse sentido, Márcia revela a importância dos aconselhamentos, das experiências e da ética enquanto elementos principais no diálogo dos pibidianos com as suas respectivas supervisoras. Questões que vão além dos conteúdos, além das estratégias, dizem respeito à personalidade profissional que se constrói gradativamente no campo de trabalho.

Modos de agir, de sentir e de viver o cotidiano escolar foram oportunizados aos pibidianos. Estes sentidos foram construídos a partir do contato com os variados âmbitos do contexto escolar, que envolve questões ligadas à gestão, ao planejamento escolar, a dinâmica das aulas de história, às intervenções em sala ente outras dimensões formativas. Isso demonstra não apenas a relevância do programa PIBID, mas, principalmente, a importância do subprojeto de História voltado especificamente à formação do profissional do ensino de História. De outro lado, mostra também as deficiências curriculares do 
próprio curso formador. Ou seja, a profissionalização, a partir da carga horária tradicional atribuída aos estágios, é permeada por lacunas que dificilmente o graduando conseguirá superar.

Quando ponderamos sobre o que pensam os pibidianos a respeito das contribuições do subprojeto para com o desenvolvimento das atividades práticas do Estágio Supervisionado, as respostas evidenciaram que a carga horária prática, exigida no Estágio, não é suficiente e que o programa PIBID foi indispensável na formação profissional, repercutindo diretamente no currículo formativo. Afirmações que podemos perceber nos relatos das bolsistas do programa:

\begin{abstract}
Vivenciei o Pibid juntamente com o estágio supervisionado, e a visão que tenho é que o Pibid é infinitamente mais completo que o estágio. Muito do que aprendi com o Pibid, em momento nenhum aprendi com o estágio. Acredito que o Pibid é o melhor aprendizado para a prática docente, o número de horas dentro de uma escola é bem maior, as tarefas são bem mais ordenadas, a percepção da realidade escolar se faz por inteiro e não apenas em uma parte (ZARPELLON, 2014).
\end{abstract}

A pibidiana Énelim ressalta o que há de mais significativo na prática docente: a experiência. Se compararmos o número de horas que um licenciando em processo de Estágio Supervisionado I e II cumpre na escola - em torno de 44 horas, sendo 20 de observação e 24 de regência - o PIBID, que se caracteriza por atividades que compreendem o mínimo de 8 horas semanais e isso ao longo de todo o ano letivo, se transforma num divisor de águas para a aquisição das habilidades e competências necessárias à profissionalização do docente em História. Énelim também destaca a possibilidade que o PIBID oportuniza em vivenciar a realidade escolar, na medida em que o trabalho de reconhecimento do campo escolar e de intervenção a partir de atividades planejadas acontece ao longo de todo o ano, e não apenas a partir de algumas horas aula, como faz compreender o estágio. Essas especificidades em torno do programa PIBID repercutem diretamente na formação da personalidade do futuro professor de História. Como destaca a pibidiana Rita Piassi:

O pibid me transformou em uma pessoa mais confiante, me fez perder aquele medo da sala de aula, porque quando estamos na graduação só entramos em sala e vemos a realidade escolar na hora do estágio, mas são poucas horas, então você não consegue 
vivenciar muito esse momento e para quem nunca esteve na sala de aula o estágio gera medo, insegurança, e o pibid nos deu a oportunidade de vivenciarmos essa realidade toda semana com intervenções, aulas diferentes contato direto com os alunos, assim quando formos para uma sala de aula vamos muito mais confiantes. Além de tudo isso a experiência adquirida vai nos acompanhar ao longo da nossa carreira, pois aprendemos na pratica o que só víamos na teoria, vivenciamos o cotidiano escolar aprendemos a realidade da escola dos alunos e passamos tanto por conflitos quanto por alegrias, o pibid é o nosso laboratório de ensino onde aprendemos sobre o dia a dia do lugar onde futuramente vamos atuar como profissionais (PIASSI, 2014).

O desencanto e certo desprestígio para com a formação à docência, como visto anteriormente, se contrastam com as afirmações de Rita. As contribuições do PIBID são significativas no tocante ao fortalecimento da identidade profissional, o que faz com que muitos pibidianos adquiram gosto pela carreira. $A$ confiança, a perda do medo da sala de aula, o planejamento de atividades diferenciadas, o contato direto com a professora titular da escola, o reconhecimento do cotidiano escolar, de seus conflitos e alegrias, etc., tudo isso repercute em experiências positivas que auxiliam na formação para a docência. O PIBID e a escola se transformam em laboratório de ensino, onde os pibidianos experimentam estratégias que buscam não apenas melhorar o ensino mas, principalmente, fortalecer a sua identidade de professor.

De forma geral, os licenciandos deparam-se com atividades práticas de ensino apenas a partir dos Estágios Supervisionados. E isso acontece a partir do terceiro ano. Ou seja, até o terceiro ano os acadêmicos nunca estiveram na posição de docentes em uma sala de aula. O estágio sintetiza a primeira oportunidade de descoberta do campo de trabalho e, consequentemente, de identificação ou não com a profissão. Se o licenciando se desencantar com a prática pode ser tarde demais, afinal já está com $75 \%$ do curso concluído, com boa parte das discussões teóricas já contempladas. O PIBID, nesse sentido, enquanto programa que é desenvolvido exclusivamente na escola, reverte esta posição. As atividades práticas são colocadas em primeiro plano. E é neste fazer e no contato direto com a realidade escolar que os pibidianos, independentemente do ano que cursam na universidade, constroem elementos de identificação com a futura profissão. 
Nesse sentido, a formação da consciência histórica passa pelo reconhecimento crítico do ambiente formativo, do cotidiano escolar e das relações travadas pelos sujeitos presentes nesse contexto. Tudo isso é essencial para o licenciando em processo de formação. Essencial na medida em que consegue estabelecer leituras críticas sobre sua própria formação e sobre as especificidades do seu trabalho enquanto professor de História. Nesse sentido, a prática do Ensino de História implica aos licenciandos buscarem o ressignificar do campo formativo e do campo de ensino. Nosso tempo implica novas posições, posturas, competências e habilidades por parte dos professores. Esta consciência é fundamental pois mostra que o trabalho docente deve ser dinâmico, atualizado e focado na função social que a disciplina, a escola e o professor assumem como compromisso formativo. Quando perguntados sobre a consciência histórica que o projeto fomenta nos futuros professores, a pibidiana Camila Alves de Oliveira assegura:

\begin{abstract}
Formar uma consciência histórica é fazer com que o aluno entenda que é um sujeito histórico e que participa diariamente da história do contexto em que está inserido. Mas antes disso é necessário que o profissional da educação tenha uma consciência histórica desenvolvida, para que perceba as ferramentas que detém e que podem ser muito úteis no despertar dessa consciência dos alunos. O PIBID contribui muito na formação desta consciência, por aproximar o acadêmico do mundo escolar, da realidade profissional e alimentar a criatividade docente. Com certeza, quem passou por essa experiência se deu conta da importância que o incentivo do professor tem em sala de aula para auxiliar o aluno nesse despertar da consciência histórica (OLIVEIRA, 2014).
\end{abstract}

A formação da consciência histórica não é uma via de mão única. Todos os envolvidos no subprojeto desenvolvem cotidianamente diferentes percepções em torno da profissão docente e do ensino de História. Formam continuamente sua consciência histórica, alimentando-a a partir de novas percepções do campo formativo e do campo de atuação. Mais ainda, a consciência da função social do professor, em especial do professor de História, é colocada em evidência sempre que os futuros profissionais do ensino vivenciam o seu campo de atuação. É fundamental que os professores saibam o que estão fazendo, o que estão ensinando, o que buscam com este conhecimento construído no diálogo cotidiano com os alunos. 
Como visto, o Programa Institucional de Bolsa de Iniciação à Docência constitui-se para os acadêmicos pibidianos em uma das mais relevantes bases de sua formação. Quando indagados a respeito dos pontos negativos da experiência vivenciada a partir dos trabalhos desenvolvidos no subprojeto, não detectamos nenhum posicionamento. Elevam-se os pontos positivos e mesmo cientes dos contratempos e dos conflitos intrínsecos ao meio escolar, como questões ligadas ao salário dos professores, a sua carga horária, a indisciplina e o desrespeito, a falta de infraestrutura das escolas, a carência de laboratórios e de ambientes virtuais de aprendizagem entre outros aspectos, os pibidianos realçam os pontos positivos, em especial, a formação de sua personalidade docente.

\section{Considerações Finais}

Como vimos o Programa institucional de Bolsa de Iniciação à Docência surgiu como proposta de governo para a valorização e aperfeiçoamento na formação de professores. Representa, em sua generalidade, características que tendem a promover, fomentar e a viabilizar aos pibidianos formas mais dinâmicas e inovadoras de tratar a disciplina em que estão inseridos, proporcionando maior valorização às licenciaturas. Sendo assim, o subprojeto PIBID História/I tem como desígnio atentar para o campo da formação docente e promover a consciência histórica e profissional dos alunos bolsistas, futuros professores.

Contatamos de forma enfática - seja pela ainda incipiente historiografia ou pela fala dos pibidianos - as contribuições do programa PIBID e do subprojeto na formação para a docência. De início, fizemos a crítica ao Projeto Político do Curso de História da Unicentro - Campus de Irati-Pr., em especial à limitada e insuficiente carga horária atribuída aos estágios supervisionados, principal e único meio de inserção dos futuros professores no ambiente de trabalho. Pudemos perceber, também, que existem contradições quanto ao perfil do futuro profissional de História que se busca formar. Contradição na medida em que se valoriza mais o perfil de pesquisador do que o perfil de docente, embora o curso seja de licenciatura. 
Olhares foram lançados com o objetivo de promover a consciência histórica e a relação dos bolsistas com mais intensidade com a escola. Muito ainda há para se fazer, mas as contribuições do PIBID são memoráveis e inegáveis na medida em que os próprios pibidianos consideram-se diferenciados por terem passado por essa experiência. As análises oriundas dos questionários respondidos pelos pibidianos foram de suma importância. De forma geral, podese perceber que houve grande desenvolvimento e ampliação da visão de mundo - ou da consciência histórica - em torno do cotidiano e da prática escolar, do conhecimento dos alunos, bem como refletir sobre a missão social de cada professor de História: construir conhecimento com os alunos, e que esses fomentem e agreguem visões que promovam a cidadania e a tomada de consciência crítica do seu mundo.

A consciência histórica, como visto, é atributo de cada sujeito. No entanto, em torno do fazer docente, a consciência implica posturas e competências que precisam ser construídas a partir do campo formativo. No caso específico do subprojeto de história da Unicentro, a formação da consciência histórica e profissional passa, entre outras dimensões: pela capacidade de perceber-se enquanto sujeito histórico, entendendo que o futuro é construído por cada um de nós; capacidade de problematizar a sociedade, principalmente partindo do contexto em que o aluno está inserido; capacidade de construir e fomentar consciência crítica em si e nos alunos; capacidade de construir conhecimento através das artes e de incentivar os alunos a pensarem historicamente.

O PIBID auxilia nesta construção positiva dos sujeitos. E se essa construção é sinônimo de ressignificação do próprio campo formativo, o pibid não deveria ser apenas para alguns acadêmicos, mas para todos. Talvez essa seja a crítica mais pertinente ao programa, que ele seja para todos os licenciandos. Pois, na medida em que apenas uma minoria é contemplada e vivencia o campo de trabalho recebendo bolsa por isso, a maioria dos licenciandos ainda está submetida a um currículo estanque e de pouca atividade prática, o que perpetua o que os pibidianos já apontaram em suas falas, a insegurança, o medo, o despreparo e o desconhecimento do próprio campo de trabalho. 
Por tudo isso, entendemos que o conceito de consciência histórica é central ao PIBID, assim como o conceito de profissionalização docente. Conceitos que se constituem pilares do subprojeto História e também do Programa PIBID. Três movimentos justificam e exemplificam esse processo: os bolsistas aprendem e aprimoram sua consciência crítica histórica através de experiências de ensino aprendizagem desenvolvidas com os alunos; promovem e vivenciam situações de profissionalização, em especial a partir das discussões com as professoras supervisoras, ou seja, com os profissionais da escola que são os professores titulares; por fim, os alunos do colégio conseguem desenvolver suas críticas e consequentemente a própria consciência histórica, através da ressignificação do ensino de História que é feita pelo grupo PIBID. Essa relação proporciona experiências que beneficiam a construção da consciência histórica nos alunos, nos futuros professores (pibidianos) e nos professores da rede pública (supervisores).

As intervenções realizadas ao longo de 2 anos de execução do subprojeto tiveram como objetivo fomentar, a partir de suas práticas, a consciência histórica dos alunos e, consequentemente a própria consciência histórica crítica dos pibidianos, enquanto profissionais do ensino de História. Isto foi feito a partir de discussões que estimularam a formação da consciência intelectual dos alunos, proporcionando aos mesmos a reflexão de seu passado e da sociedade como um todo, objetivando que estes se sentissem sujeitos da própria história, dando sentido a seu passado e justificando seu presente/futuro. Como defende Rüsen (2001. p. 57-58):

E este é o caso quando se entende por consciência histórica a suma das operações mentais com as quais os homens interpretam sua experiência da evolução temporal de seu mundo e de si mesmos, de forma que possam orientar, intencionalmente, sua vida prática no tempo.

Consciência histórica e pensamento histórico, nesse sentido, parecem se combinar enquanto operação mental para a compreensão da experiência temporal. O Professor Luís Fernando Cerri discorre sobre o pensamento histórico levando em consideração principalmente o que Rüsen e Heller pensam. Para ambos, segundo Cerri (2001, p.100), pensar historicamente é um fenômeno 
antes de mais nada cotidiano e inerente a condição humana, antes de ser cultural ou opcional é natural. Todo ser humano é capaz de pensar historicamente. $\mathrm{O}$ conhecimento acadêmico acaba por ser apenas mais complexo e especializado, mas não superior ao dos alunos da educação básica. Quanto ao pensar historicamente Cerri afirma (2011, p. 59):

[...] pensar historicamente é nunca aceitar as informações, ideias, dados etc., sem levar em consideração o contexto em que foram produzidos: seu tempo, suas peculiaridades culturais, suas vinculações com posicionamentos políticos e classes sociais, as possibilidades e limitações do conhecimento que se tinha quando se produziu o que é posto em análise.

Essa deve ser a constante busca do professor de História, formar uma consciência histórica no aluno e desenvolver o pensamento histórico do mesmo, procurando principalmente desenvolver a consciência intelectual e crítica, afim de que se entenda como sujeito da História. Neste sentido a realidade social é o ponto de partida e de chegada do Ensino e aprendizagem de História (CAIMI, 2001).

Aproximar a realidade do aluno, as experiências vivenciadas por ele e as relações que foram se formando com o passado, pode possibilitar na dinâmica do ensino a formação da consciência histórica crítica do aluno, em especial do pibidiano. Formação essa que refletirá nas escolas quando esses tornarem-se profissionais do Ensino. No caso do PIBID esse contato e troca já acontecem. Portanto, a Universidade constitui um espaço formador de consciência intelectual e crítica, no qual têm a responsabilidade de dar aporte necessário para que o desenvolvimento de habilidades aconteça e que a formação docente seja voltada à sociedade.

O ensino de História em si vem passando por várias modificações, inventando e se reinventando, por essa óptica podemos observar que o ensino que é produzido na academia e o da escola está em constante debate, mas ao mesmo tempo devem estar em devotado diálogo, considerando a possibilidade de um acrescentar ao outro, sem qualificar ou desqualificar, mas validando ambos e respeitando-os mutuamente. Neste sentido a função do ensino de História, caracteriza-se principalmente por estar pautada em promover o desenvolvimento do pensamento crítico e reflexivo, portanto da consciência 
histórica dos alunos para a cidadania. Como afirmam Bispo e Lopes ( 2010, p. 81-82):

\begin{abstract}
Pressupõe-se que o ensino de História requer a idéia de participação, de trabalho orientado por uma vontade coletiva, ou seja, o processo ensino aprendizagem de História na educação básica requer atividades interdisciplinares visando à construção do conhecimento de forma horizontal, onde educador e educando tenham visões múltiplas dos diversos contextos históricos. Por isso, a escola como um organismo social precisa trabalhar coletivamente, promovendo o desenvolvimento do cidadão crítico e reflexivo.
\end{abstract}

Para que a "construção de conhecimento" aconteça, é necessário que os professores tenham conhecimento das teorias, mas que também saibam usá-las nas visões que estabelecem da sociedade. Acima de tudo, que tenham consciência histórica para interpretar o presente vivido. A academia precisa construir e incentivar meios de proporcionar essa prática no decorrer do processo de profissionalização, sendo, atualmente, o PIBID um dos exemplos. Partindo dessa concepção, o Subprojeto PIBID de História da Unicentro, desenvolvido no campus de Irati-Pr., entende a convivência dos futuros professores no cotidiano escolar como propiciadora de um entendimento entre o pensamento científico e o pensamento comum, contribuindo, desse modo, para uma maior compreensão do papel do professor de História, tanto no sentido social quanto político, mas principalmente na perspectiva humanizadora.

\title{
Referências:
}

BARCA, I. Aula oficina: do projecto à avaliação. In: BARCA, I. (Org.). Para uma educação Histórica de qualidade. Actas das quartas jornadas Internacionais de Educação Histórica. Universidade do Minho, Braga-Portugal, 2004.

BARROSO, V. L. M. Formação de professores em história no tempo presente: Estágios de docência e Pibid - quais conexões? Revista Latino-Americana de História. v. 2, n. 6, Edição Especial, ago./2013. p.10-24.

BISPO JR, J. S.; LOPES, A. Ensinar requer dinamismo: os desafios do ensino de História na construção da cidadania. Diálogos \& Ciência. Revista da Rede de Ensino FTC. Ano IV, n. 13, jun./2010.

CAIMI, F. E. Conversas e controvérsias: o ensino de história no Brasil (19801998). Passo Fundo: UPF, 2001. 
CERRI, L. F. Ensino de história e consciência histórica, implicações didáticas de uma discussão contemporânea. Rio de Janeiro: Editora FGV, 2011.

Os conceitos da Consciência Histórica e os desafios da Didática da História". Revista de História Regional. v. 2, n. 6, Inverno 2001, p. 93-112. PARANÁ. Diretrizes curriculares da educação básica. História. SEED. Paraná, 2008.

GONSALÉZ, F. J.; RODRIGUES, L. S. Consciência histórica, Ensino de História e formação inicial: primeiras indagações. XVIII Jornada de pesquisa UNIJUÍ. 2013.

LINHARES, A. M.; PEREIRA, I. C. Experiências do PIBID-História/2009 na Escola Estadual Padre Rômulo Zanchi: o Potencial Didático do Cinema no Ensino de História e a discussão acerca da Temática da Identidade, Identificação e o Sistema de Cotas nas Instituições Públicas. Revista Latino-Americana de História. v. 2, n. 6, Edição Especial, Ago./2013.pp.1103-1113.

MEINERZ, C. B. Estágios de docência e PIBID: impactos inimagináveis no campo do Ensino de História. Revista Latino-Americana de História. v. 2, n. 6, Edição Especial, Ago./2013. pp. 223-234.

MONTEIRO, A. M. F.C.; GASPARELLO, A. M; MAGALHÃES, M. de S. (Org.). Ensino de História: Sujeitos, saberes e práticas. Rio de Janeiro: Mauad X, FAPERJ, 2007. $\mathrm{X}, 2007$.

Professores de História: entre saberes e práticas. Rio de Janeiro: Mauad

PRADO, D. P.; MACEDO, S. M. Reflexões acerca do ensino de História: a História Local e a Consciência Histórica. Revista Latino-Americana de História. v. 2, n. 6, Edição Especial. Ago./2013, pp.1197-1210.

PPCH - Projeto Político do Curso de História. Unicentro, Campus de Irati-Pr., 2010.

DEHIS. Regulamento de Estágio. Curso de História. UNICENTRO, Campus de Irati. CONDEP; 2009.

RIBEIRO, D. M.; CASTELA, G. da S.; JUSTINA, L. D. (Org.). Formação de Professores no Paraná: o PIBID em foco. Porto Alegre: Evangraf/UNIOESTE, 2014. (Coleção PIBID).

RÜSEN, J. Razão Histórica: fundamentos da ciência histórica. Brasília: Editora Universidade de Brasília, 2001.

SARTORI, J. Formação de professores: conexões entre saberes da universidade e fazeres na educação básica. Anais de evento: Formação de Professores.

Universidade federal do Rio Grande do Sul. Porto Alegre, 2011.

SCHNEIDER, C. I. Subprojeto PIBID-História de Irati. Unicentro, Campus de Irati; $\mathrm{MEC} / \mathrm{CNPq}, 2012$.

Regiões no campo formativo da História: espaço liso e estriado. In:

ANSELMO, B.; SOCHODOLAK, H.; ARIAS NETO, J. M. (Org.). A escrita da História: fragmentos de historiografia contemporânea. Ponta Grossa: ANPUH-PR, 2013. 


\section{Entrevistas/questionário}

GONÇALVES, Willian Franco. Bolsista PIBID do subprojeto História - Período: agosto de 2012 a fevereiro de 2014. Questionário respondido à Silvéria da Aparecida Ferreira. Arquivo particular. Fevereiro de 2014.

JESUS, Edison Luiz de. Bolsista PIBID do subprojeto História - Período: setembro de 2013 a fevereiro de 2014. Questionário respondido à Silvéria da Aparecida Ferreira. Arquivo particular. Fevereiro de 2014.

KAMINSKI, Adriane do Rocio. Bolsista PIBID do subprojeto História - Período: agosto de 2012 a fevereiro de 2014. Questionário respondido à Silvéria da Aparecida Ferreira. Arquivo particular. Fevereiro de 2014.

OLIVEIRA, Camila Alves de. Bolsista PIBID do subprojeto História - Período: setembro de 2013 a fevereiro de 2014. Questionário respondido à Silvéria da Aparecida Ferreira. Arquivo particular. Fevereiro de 2014.

OLIVEIRA, Geovane Gonçalves de. Bolsista PIBID do subprojeto História Período: setembro de 2013 a fevereiro de 2014. Questionário respondido à Silvéria da Aparecida Ferreira. Arquivo particular. Fevereiro de 2014.

PIASSI, Rita. Bolsista PIBID do subprojeto História - Período: agosto de 2012 a fevereiro de 2014. Questionário respondido à Silvéria da Aparecida Ferreira. Arquivo particular. Fevereiro de 2014.

POCHAPSKI, Gabriel José. Bolsista PIBID do subprojeto História - Período: agosto de 2012 a julho de 2013. Questionário respondido à Silvéria da Aparecida Ferreira. Arquivo particular. Fevereiro de 2014.

SCAVINSKI, Márcia. Bolsista PIBID do subprojeto História - Período: agosto de 2012 a fevereiro de 2014. Questionário respondido à Silvéria da Aparecida Ferreira. Arquivo particular. Fevereiro de 2014.

STRUGALA, Valdinéia. Bolsista PIBID do subprojeto História - Período: agosto de 2012 a fevereiro de 2014. Questionário respondido à Silvéria da Aparecida Ferreira. Arquivo particular. Fevereiro de 2014.

ZARPELLON, Énelim. Bolsista PIBID do subprojeto História - Período: agosto de 2012 a fevereiro de 2014. Questionário respondido à Silvéria da Aparecida Ferreira. Arquivo particular. Fevereiro de 2014. 